\title{
ADSORÇÃO DAS PROTEINAS ALBUMINA DO SORO BOVINO E $\alpha$ - LACTOALBUMINA EM CARVÃO ATIVADO OBTIDO A PARTIR DO ENDOCARPO DO COCO
}

\author{
K. A. MONTEIRO ${ }^{1 *}$; J. F.BORGES ${ }^{2}$; T. P. OLIVEIRA ${ }^{3}$; M. J. P. BRITO ${ }^{4}$; S.N.ANDRADE ${ }^{5}$; C. \\ M. VELOSO ${ }^{6}$. \\ ${ }^{1,2,3}$ Universidade Estadual do Sudoeste da Bahia, Graduação em de Engenharia de Alimentos \\ ${ }^{4,5}$ Universidade Estadual do Sudoeste da Bahia, Programa de Pós-Graduação em Engenharia e \\ Ciência de Alimentos \\ ${ }^{6}$ Universidade Estadual do Sudoeste da Bahia, Departamento de Ciências Naturais \\ *e-mail: keivison_almeida@ hotmail.com
}

\begin{abstract}
RESUMO
Este trabalho teve como objetivo produzir carvões ativados utilizando como precursor de carbono o endocarpo do coco e avaliar seu desempenho no processo adsortivo das proteínas $\alpha$-lactoalbumina $(\alpha-L a)$ e Albumina do Soro Bovino $(B S A)$. O carvão foi preparado pelo método de ativação química, utilizando o ácido fosfórico $\left(\mathrm{H}_{3} \mathrm{PO}_{4}\right)$ como agente de ativação, com razão de impregnação (massa do ativante/massa da amostra) na proporção de 2:1. A carbonização dos materiais foi realizada em forno mufla na temperatura de $500{ }^{\circ} \mathrm{C}$, sob fluxo de nitrogênio. Foram determinados o teor de umidade, cinzas e rendimento do adsorvente obtido. A eficiência do processo de adsorção das proteínas foi determinada através do estudo do $\mathrm{pH}$ e de massa. No estudo de $\mathrm{pH}$ verificou-se que o melhor desempenho do processo de adsorção foi obtido em $\mathrm{pH}$ 5,0, para a adsorção da $\alpha$-lactoalbumina $(\alpha-L a)$ e pH 3 para a Albumina do Soro Bovino $(B S A)$, indicando que esse $\mathrm{pH}$ é o mais adequado para realizar os testes adsortivos. Através do estudo realizado para analisar a influência da massa de carvão sobre a capacidade de adsorção das proteínas, pode-se observar que a massa que apresentou maior capacidade de adsorção foi $0,075 \mathrm{mg}$ para ambas as proteínas, sendo que para a adsorção da $\alpha$-lactoalbumina obteve-se uma eficiência máxima de $38 \%$ e na adsorção da Albumina do Soro Bovino uma eficiência de $15 \%$.
\end{abstract}

\section{INTRODUÇÃO}

O soro de leite bovino é um produto resultante da precipitação de gorduras e caseínas do leite durante a fabricação de queijos. Este produto representa de 85 a $90 \%$ do volume de leite e retém $55 \%$ de seus nutrientes, dentre eles a lactose $(4$ a $5 \%)$ e proteínas $(0,6$ a $0,7 \%)$. Proteínas de soro de leite bovino são definidas como aquelas que permanecem retidas no soro do leite depois de coagulação da caseína a $20^{\circ} \mathrm{C}$ e pH 4,6. O soro contém aproximadamente $20 \%$ das proteínas originais do leite. As principais proteínas no soro de leite são a $\alpha$-lactoalbumina $(\alpha-L a)$ e a $\beta$-lactoglobulina $(\beta$-Lg), que representam aproximadamente $70 \%$ do total proteico contido nele. Além dessas, são encontradas a albumina do soro bovino, imunoglobulinas, glicomacropeptídeos e lactoferrina. (SGARBIERI, 2005; HARAGUCHI, ABREU \& DE PAULA, 2006). 
A $\alpha$-lactoalbumina $(\alpha-L a)$ é a segunda maior fração protéica presente no soro do leite, correspondendo a $20-25 \%$ das proteínas do soro e $2 \%$ do leite, numa concentração 1,0 a $1,5 \mathrm{~g} / \mathrm{l}$. É rica em aminoácidos essenciais, principalmente o triptofano, um aminoácido precursor de niacina, vitamina hidrossolúvel, cujos derivados desempenham um importante papel no metabolismo energético celular. Sua molécula é formada por 123 resíduos de aminoácidos e tem um peso molecular de aproximadamente $14 \mathrm{kDa}$ e ponto isoelétrico entre 4,7 e 4,9 (KRISSANSEN, 2007; RENHE, 2008).

A albumina do soro bovino ( $B S A)$ é uma proteína globular de grandes dimensões (69 $\mathrm{kDa}$ ) com um bom perfil de aminoácidos essenciais. Está presente no soro do leite em teores de 0,1 a $0,4 \mathrm{~g} / \mathrm{L}$. Consiste em cadeia polipeptídica simples contendo cerca de 582 aminoácidos com dezessete ligações dissulfídicas intramoleculares. $\mathrm{O}$ seu ponto isoelétrico é próximo a 5,13 (ANTUNES, 2003).

Acredita-se que aproximadamente 50\% de todo soro liquido produzido não é aproveitado, sendo esse número ainda maior se forem consideradas as micro e pequenas empresas (LIRA et al., 2009). O tratamento do soro do leite além de ser um dos fatores para minimizar os impactos ambientais permitem o isolamento total ou parcial dos componentes que constitui esse coproduto (OLIVIERA, 2014).

Diferentes tipos de operações unitárias vêm sendo utilizadas para recuperação ou purificação dessas biomoléculas, entre esses mecanismos pode-se destacar o processo de adsorção. A adsorção consiste em um fenômeno físico-químico em que o componente em fase líquida é transferido para a superfície de uma fase sólida. Os componentes que se unem à superfície são chamados adsorvatos, enquanto que a fase sólida que retém o adsorvato é chamada adsorvente. A remoção das moléculas a partir da superfície é chamada dessorção (MASEL, 1996).

A migração dos componentes em fase líquida de uma fase para outra tem como força motriz a diferença de concentrações entre o seio do fluido e a superfície do adsorvente. Usualmente, o adsorvente é composto de partículas que são empacotadas em um leito fixo por onde passa a fase fluida continuamente até que o equilíbrio seja atingido. Como o adsorvato concentra-se na superfície do adsorvente, quanto maior for esta superfície, maior será a eficiência da adsorção. Por isso, geralmente, os adsorventes são sólidos com partículas porosas (BORBA, 2006).

Vários adsorventes podem ser utilizados nos processo adsortivos, entre eles destaca-se o carvões ativados, que são materiais carbonosos porosos que apresentam uma forma microcristalina, não grafítica, que sofreram um processamento para aumentar a porosidade interna. Uma vez ativado, o carvão apresenta uma porosidade interna comparável a uma rede de túneis que se bifurcam em canais menores e assim sucessivamente. A maior parte dos materiais carbonáceos possui um certo grau de porosidade, com área superficial variando entre 10 e $15 \mathrm{~m}^{2} \cdot \mathrm{g}^{-1}$. No decorrer da ativação a área superficial aumenta com a oxidação dos átomos de carbono. Após a ativação, o carvão pode apresentar área superficial acima de $800 \mathrm{~m}^{2} \mathrm{~g}^{-1}$ (CLAUDINO 2003; MINOZZO, 2000).

Quase todos os materiais que possuem um alto teor de carbono podem ser utilizados na obtenção de carvões ativados. Os precursores utilizados são cascas de coco, de arroz, de nozes, carvões minerais (antracita, betuminoso, linhito), madeiras, turfas, resíduos de petróleo, ossos de animais, caroços de pêssego, de damasco, de amêndoa, de ameixa, de azeitona e grão de café, entre outros 
materiais carbonáceos. (CLAUDINO, 2003; GONÇALVES et al., 2006).

A capacidade adsortiva do carvão ativado em relação a um adsorvato específico depende de fatores intrínsecos do adsorvente, resultantes basicamente, da forma de ativação e do material de produção, tais como: volume e distribuição de poros, forma dos poros, existência de grupos funcionais de superfície, $\mathrm{pH}$, teor de cinzas entre outros. Por outro lado, as condições experimentais como $\mathrm{pH}$, temperatura, tempo de contato requerido, agitação e presença de compostos que competem pelos mesmos sítios de adsorção, atuam diretamente na eficiência da adsorção, podendo favorecer ou dificultar o processo (KURODA, 2005).

A proposta de utilizar o carvão ativado obtido a partir de resíduos agroindustriais na remoção de proteínas no soro do leite em meio aquoso, é relevante perante a demanda de recuperação das biomoléculas de interesse comercial existente no soro do leite. Portanto, o presente trabalho teve como objetivo produzir carvão ativado a partir do endocarpo do coco e avaliar a sua capacidade em adsorver as proteínas Albumina do Soro Bovino (BSA) e a $\alpha$-lactoalbumina ( $\alpha$-La), proteínas presentes no soro do leite.

\section{MATERIAIS E MÉTODOS}

O experimento foi realizado no Laboratório de Engenharia de Processos (LEP) da Universidade Estadual do Sudoeste da Bahia (UESB), Campus de Itapetinga.

Para a síntese do carvão ativado $(C A)$ o endocarpo do coco foi triturado e seco em estufa a $105^{\circ} \mathrm{C}$ por $24 \mathrm{~h}$, em seguida foi moído e peneirado em uma peneira de 40 mesh. $\mathrm{O}$ material percussor obtido foi lixiviado com uma solução de $\mathrm{NaOH}$ a 0,5 mol.L $\mathrm{L}^{-1}$ e levado a ebulição a $100{ }^{\circ} \mathrm{C}$ por $60 \mathrm{~min}$, em refluxo. Finalmente, foi lavado com água destilada até atingir o $\mathrm{pH}$ 7,0 e seco por $24 \mathrm{~h}$.
O material precursor foi então impregnado com ácido fosfórico (1g de precursor $/ 2 \mathrm{~g}$ de agente ativante) com agitação manual por 30 min e seco em estufa por $24 \mathrm{~h}$. A carbonização do material em estudo foi realizado em forno tipo mufla sob fluxo de nitrogênio $\left(100 \mathrm{ml}_{\mathrm{min}}^{-1}\right)$ com taxa de aquecimento de $5^{\circ} \mathrm{C} \cdot \mathrm{min}^{-1}$ até $500{ }^{\circ} \mathrm{C}$, permanecendo nessa temperatura por $30 \mathrm{~min}$. O material foi imerso em uma solução de ácido clorídrico 0,1 mol. $\mathrm{L}^{-1}$ e levado à ebulição por um período de $60 \mathrm{~min}$, em refluxo e finamente lavado com água destilada até obter o $\mathrm{pH} 7,0$ e seco a $105^{\circ} \mathrm{C}$ durante 24 h.

O carvão obtido foi caracterizado quanto ao ter de cinzas e umidade. A quantidade de cinzas do carvão ativado foi determinada por incineração do material em forno tipo mufla a $600{ }^{\circ} \mathrm{C}$, segundo metodologia descrita por Silva e Queiroz, (2002). O teor de umidade foi determinado de acordo com as normas do Instituto Adolfo Lutz (2004). O rendimento percentual do carvão (\%) foi determinado pela razão massa do carvão obtido (g) pela massa do precursor $(\mathrm{g})$.

Para a determinação do ponto de carga zero, $50 \mathrm{mg}$ da amostra de carvão foi colocada em contato com $50,00 \mathrm{~mL}$ de uma soluções de cloreto de sódio $(\mathrm{NaCl}) \quad 0,10 \mathrm{~mol} \mathrm{~L}^{-1} \mathrm{em}$ diferentes valores de $\mathrm{pH}$ (1-11) e deixados sobre agitação constante durante $24 \mathrm{~h}$. $\mathrm{O}$ pH de cada solução foi ajustado com solução de ácido clorídrico $(\mathrm{HCl})$ ou hidróxido de sódio $(\mathrm{NaOH}) 0,50 \mathrm{~mol} \mathrm{~L}^{-1}$. Ao final das $24 \mathrm{~h} \mathrm{o} \mathrm{pH}$ final foi medido e construído o gráfico, onde o ponto de carga zero corresponde à faixa onde o $\mathrm{pH}$ final se mantém constante.

A avaliação da capacidade de absorção dos carvões foi realizada utilizando como moléculas modelos a Albumina do Soro Bovino - BSA e a $\alpha$-lactoalbumina $(\alpha-L a)$.

Para avaliar o efeito do $\mathrm{pH}$ no processo adsortivo foram realizados testes variando o $\mathrm{pH}$ inicial das soluções. Aproximadamente 25 
mg do carvão ativado foi adicionado em tubos de ensaio contendo $5 \mathrm{~mL}$ da solução de cada proteína na concentração de $500 \mathrm{mg} . \mathrm{L}^{-1} \mathrm{em}$ diferentes valores de $\mathrm{pH}(3,0 ; 5,0 ;$ e 7,0$)$. O ajuste do $\mathrm{pH}$ foi realizado com adição de solução tampão fosfato de potássio $20 \mathrm{mM}$ para pH 7,0 e 5,0 e utilizado fosfato de potássio monobásico e ácido fosfórico para pH 3,0. Os tubos ficaram em agitação constante (20rpm) à $24^{\circ}\left( \pm 1^{\circ} \mathrm{C}\right)$ por $24 \mathrm{~h}$, em seguida foram centrifugados, sendo o sobrenadante extraído com auxilio de uma seringa. A quantificação da proteína foi realizada por leitura direta em espectrofotômetro no comprimento de onda de 280nm.

Para avaliar a influencia da massa do carvão no processo de adsorção das proteínas, foi realizado um estudo com diferentes massas do adsorvente $(0,025 \mathrm{~g}, 0,050 \mathrm{~g}$ e $0,075 \mathrm{~g})$, adicionada a $5 \mathrm{ml}$ de solução de cada proteína com concentração inicial de $500 \mathrm{mg} . \mathrm{L}^{-1}$ no pH escolhido, seguindo a mesma metodologia para o estudo do efeito do $\mathrm{pH}$.

\section{RESULTADO E DISCUSSÃO}

Os resultados obtidos para caracterização química e o rendimento do carvão estão apresentados na Tabela 1 .

Tabela 1. Teores de umidade e cinza e rendimento do carvão ativado

\begin{tabular}{ccc}
\hline $\begin{array}{c}\text { Umidade } \\
(\%)\end{array}$ & Cinzas (\%) & $\begin{array}{c}\text { Rendimento do } \\
\text { carvão ativado }(\%)\end{array}$ \\
\hline 5,58 & 19,13 & 30 \\
\hline
\end{tabular}

Fonte: Autor (2015)

O carvão ativado em estudo apresentou um teor de umidade dentro dos padrões estabelecidos para esse tipo de material, pois segundo Fernandes (2004) para maior eficiência no processo adsortivo, menor tem que ser o seu teor de umidade. Existe um grande interesse em se obter carvões com baixos teores de umidade, pois a molécula de água ocupa a superfície ativa do sólido, reduzindo a atividade do adsorvente.

As cinzas são impurezas minerais acrescidas à massa do carvão por intermédio das ações da ativação e pirolise, através da combinação entre materiais orgânicos e inorgânicos. O conteúdo de cinzas é muito importante, principalmente na adsorção em soluções, pois dependendo do solvente usado, parte das cinzas podem ser extraídas contaminando e mudando o $\mathrm{pH}$ da solução (SMÍSEK, 1967). Dessa forma é desejável que os carvões apresentem baixo teor de cinzas. Como é possível observar (Tabela 1) o adsorvente obtido apresentou um alto teor de cinzas, valor este superior ao reportado por Radhika e Palanivelu (2006) ao sintetizar carvões ativados a partir do endocarpo do coco $(2,13 \%)$. O alto ter de cinzas encontrado no carvão ativado pode estar relacionado ao método de ativação e ao fato dos componente inorgânicos presentes no material de partida não terem sido removidos efetivamente na lixiviação alcalina ficando retido no material precursor.

$\mathrm{O}$ valor encontrado para o rendimento do carvão ativado foi de $30 \%$, estando de acordo com valores encontrado na literatura para carvões produzidos utilizando como precursor resíduos agroindustriais.

Foi observado que o $\mathrm{pH}$ do ponto de carga zero $\left(p H_{P C Z}\right)$ do carvão ativado em estudo está na faixa de pH 3,6 ( Figura 1). A superfície do carvão é positivamente carregada quando o $\mathrm{pH}$ da solução é menor que o ponto de carga zero e negativamente carregada quando o pH da solução é mais alta que o ponto de carga zero (BANSAL \& GOYAL, 2005).

Vieira et al. (2010) afirmam que em soluções com pH abaixo do ponto de carga zero a superfície do carvão ativado é protonada, favorecendo a adsorção de compostos com carga negativa, e 
conseqüentemente é desprotonada em $\mathrm{pH}$ acima, favorecendo o comportamento oposto.

Figura 1 - Ponto de carga zero do carvão ativado.

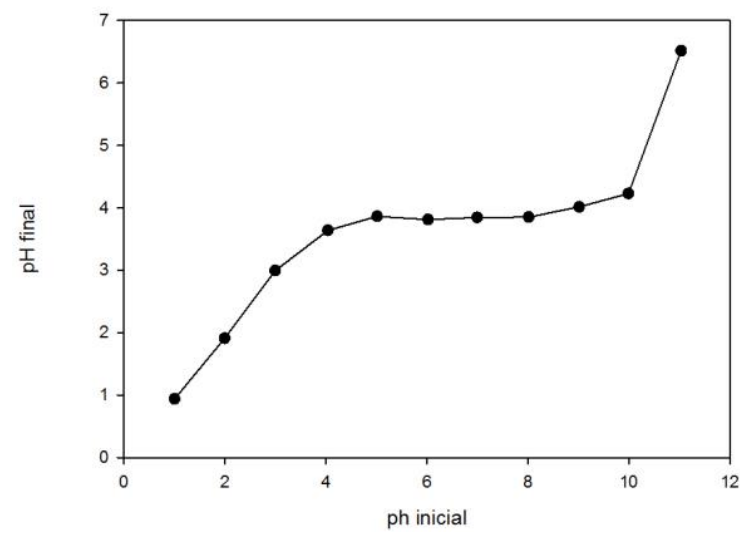

Fonte: Autor (2015)

Cambuim (2009) ao determinar o $\mathrm{pH}$ do ponto de carga zero de carvão ativado produzido a partir de endocarpo de coco e ácido fosfórico, observou que o $p H_{P C Z}$ do carvão foi 4,31, já Andrade et al. (2014) utilizando mesmo precursor obteve o ponto de carga de $\mathrm{pH} 7,1$. Isso evidência que a forma de com o carvão é obtido influência no ponto de carga zero do adsorvente.

Os resultados de estudo da variação do $\mathrm{pH}$ no processo de adsorção da proteína Albumina do soro bovino ( $B S A)$ no carvão ativado obtido a partir do endocarpo do coco são apresentados na Tabela 2. Através do estudo de $\mathrm{pH}$ foi possível constatar que a medida que se reduzia o $\mathrm{pH}$ da solução, houve um aumento na eficiência da adsorção, sendo que em pH 3 obtêm-se os melhores valores para a capacidade adsortiva $(q)$ e eficiência (Efic), demostrando que este $\mathrm{pH}$ é ideal para a realização dos testes posteriores. Mudanças no $\mathrm{pH}$ afetam o processo adsortivo por meio da dissociação de grupos funcionais presentes nos sítios ativos do adsorvente (MALL, SRIVASTAVA e AGARWAL, 2006).
Tabela 2. Concentração na solução (C), capacidade adsortiva $(q)$ e eficiência de adsorção (efic) da proteína Albumina do soro bovino (BSA).

\begin{tabular}{ccccc}
\hline Amostra & $\mathrm{pH}$ & $\begin{array}{c}C \\
\left(\mathrm{mg} . \mathrm{L}^{-1}\right)\end{array}$ & $\begin{array}{c}q \\
\left(\mathrm{mg}^{-} \mathrm{g}^{-1}\right)\end{array}$ & $\begin{array}{c}\text { Efic } \\
(\%)\end{array}$ \\
\hline$C A$ & 3,0 & 470,68 & 5,85 & 5,86 \\
$C A$ & 5,0 & 482,78 & 3,46 & 3,44 \\
$C A$ & 7,0 & 490,99 & 1,80 & 1,80
\end{tabular}

Fonte: Autor (2015)

Os resultados coletados em relação ao estudo da variação do $\mathrm{pH}$ no processo de adsorção da proteína $\alpha$-lactoalbumina $(\alpha-L a)$ no carvão ativado são apresentados na Tabela 3.

Tabela 3. Concentração na solução $(C)$, capacidade adsortiva $(q)$ e eficiência de adsorção (efic) da proteína $\alpha$-lactoalbumina $(\alpha-L a)$.

\begin{tabular}{ccccc}
\hline Amostra & $\mathrm{pH}$ & $\begin{array}{c}C \\
\left(\mathrm{mg.L}^{-1}\right)\end{array}$ & $\begin{array}{c}q \\
\left(\mathrm{mg} \cdot \mathrm{g}^{-1}\right)\end{array}$ & $\begin{array}{c}\text { Efic } \\
(\%)\end{array}$ \\
\hline$C A$ & 3,0 & 444,4 & 11,0 & 11,1 \\
$C A$ & 5,0 & 328,6 & 34,1 & 34,2 \\
$C A$ & 7,0 & 357,3 & 28,4 & 28,5 \\
\hline
\end{tabular}

Fonte: Autor (2015)

$\mathrm{O}$ estudo de $\mathrm{pH}$ realizado com a proteína $\alpha$-lactoalbumina $(\alpha-L a)$ demonstrou que em pH 5,0 são obtidos os valores mais expressivos tanto para a capacidade adsortiva $(q)$ quanto sua eficiência (Efic), constatando que este é o $\mathrm{pH}$ adequado para os próximos testes. Esse valor de $\mathrm{pH}$ é o mais próximo do ponto isoelétrico da proteína e do $p H_{P C Z}$ do carvão, o que demonstra que a adsorção ocorre apenas devido ao efeito do tamanho de poros e da área do carvão. Como a molécula do $\alpha$-La é menor que a do $B S A$ a capacidade adsortiva foi maior.

Pereira (2012) utilizando o carvão ativado produzido a partir da casca de cacau e caroço de siriguela, impregnados com ácido fosfórico $\left(\mathrm{H}_{3} \mathrm{PO}_{4}\right)$ e cloreto de $\mathrm{zinco}\left(\mathrm{ZnCl}_{2}\right)$, obteve $\mathrm{pH}$ 7,0 com os melhores valores de capacidade adsortiva e eficiência, para as 
proteínas Albumina do soro bovino $(B S A)$ e $\alpha$ lactoalbumina $(\alpha-L a)$. Isso evidência que o tipo de material utilizado para a síntese do carvão e a sua impregnação influência nas características adsortivas das proteínas em estudo.

O estudo de massa foi realizado para analisar a influência da massa de carvão frente à adsorção das proteínas $B S A$ e $\alpha-L a$. Os resultados obtidos para esse estão apresentados nas Tabelas 4 e 5.

Tabelas 4. Concentração na solução (C), capacidade adsortiva $(q)$ e eficiência de adsorção (efic) da proteína Albumina do soro bovino (BSA).

\begin{tabular}{ccccr}
\hline Amostra & $\begin{array}{c}\text { Massa } \\
(\mathrm{mg})\end{array}$ & $\begin{array}{c}C \\
\left(\mathrm{mg} . \mathrm{L}^{-1}\right)\end{array}$ & $\begin{array}{c}q \\
\left(\mathrm{mg} \cdot \mathrm{g}^{-1}\right)\end{array}$ & $\begin{array}{c}\text { Efic } \\
(\%)\end{array}$ \\
\hline$C A$ & 0,025 & 461,1 & 7,7 & 7,78 \\
$C A$ & 0,050 & 466,3 & 6,7 & 6,73 \\
$C A$ & 0,075 & 424,5 & 5,0 & 15,09 \\
\hline
\end{tabular}

Fonte: Autor (2015)

É possível observar (Tabela 4) que o aumento da massa do adsorvente promoveu a um aumento na eficiência da adsorção da $B S A$, atingindo uma eficiência máxima de 15,09\% com a massa de 0,075 g. Esses resultados demonstram que mesmo aumentando a massa do carvão a capacidade adsortiva ainda é baixa para a molécula em estudo, demonstrando que o efeito dominante no processo é o de acesso aos poros do material adsorvente.

Comportamento semelhante foi observado para a adsorção da $\alpha$-lactoalbumina (Tabela 5), onde a eficiência máxima da adsorção $(38,13 \%)$, foi atingida com a maior massa avaliada.
Tabela 5. Concentração na solução $(C)$, capacidade adsortiva $(q)$ e eficiência de adsorção (efic) da proteína $\alpha$-lactoalbumina $(\alpha-L a)$.

\begin{tabular}{ccrrr}
\hline Amostra & $\begin{array}{c}\text { Massa } \\
(\mathrm{mg})\end{array}$ & $\begin{array}{c}\mathrm{C} \\
\left(\mathrm{mg} \cdot \mathrm{L}^{-1}\right)\end{array}$ & $\begin{array}{c}\mathrm{q} \\
\left(\mathrm{mg} \cdot \mathrm{g}^{-1}\right)\end{array}$ & $\begin{array}{l}\text { Efic } \\
(\%)\end{array}$ \\
\hline$C A$ & 0,025 & 336,7 & 32,5 & 32,6 \\
$C A$ & 0,050 & 319,7 & 18,0 & 36,0 \\
$C A$ & 0,075 & 309,3 & 12,7 & 38,1 \\
\hline
\end{tabular}

Fonte: Autor (2015)

Os baixos valores de eficiência e capacidade adsortiva observados para os estudos realizados demonstram que o elevado teor de cinzas do carvão compromete a sua capacidade de adsorção, pois as mesmas bloqueiam o acesso aos poros do carvão. Desta forma, a metodologia de síntese deve ser modificada com o objetivo de se obter materiais com menor teor de cinzas.

\section{CONCLUSÃO}

A partir das analises dos resultados obtidos pode-se concluir que o endocarpo do coco pode ser utilizado como material precursor para a síntese de carvão ativado, porém a metodologia de síntese deve ser melhorada no intuito de reduzir o teor de cinzas do carvão. Os testes adsortivos realizados mostram que o melhor $\mathrm{pH}$ para a adsorção da $\alpha$-lactoalbumina foi o $\mathrm{pH} \mathrm{5,0} \mathrm{e}$ que a melhor massa para adsorção foi de 0,075g apresentando uma eficiência de $38 \%$. Para a adsorção da proteína Albumina do soro bovino o $\mathrm{pH}$ 3,0 deve ser empregado com uma massa também de 0,075g $($ Efic $=15 \%)$. Diante disso pode concluir que o carvão ativado obtido apresenta melhores características para a adsrorção do $\alpha-L a$, devido ao seu menor tamanho, quando comparada a $B S A$ nas condições do estudo.

\section{NOMENCLATURA}


$B S A=$ Albumina do Soro Bovino

$\alpha$ - $L a=\alpha$-lactoalbumina

$C=$ Concentração da solução no equilíbrio

$C A=$ Carvão ativado com ácido fosfórico

efic $=$ Eficiência da adsorção

$p H_{P C Z}=\mathrm{pH}$ de ponto de carga zero

$q=$ Capacidade adsortiva

\section{REFERÊNCIAS}

ANDRADE, S.N.; VELOSO, C.M.; FONTAN, R.C.I.; BONOMO, R.C.F. Adsorção da $\beta$-lactalbumina em carvão ativado obtido a partir de endocarpo de coco. Anais do 54 Congresso brasileiro de química. 2014.

ANTUNES, A. J. Funcionalidade de proteínas do soro de leite bovino. São Paulo: Manole Ltda, 2003.

AYGÜN, A.; YENISOY-KARAKAS, S.; DUMAN, I., Production of granular activated carbon from fruit stones and nutshells and evaluation of their physical, chemical and adsorption properties, Microporous and esoporous Materials. V.66, 189p., 2003.

BANSAL, R. C.; GOYAL, M. Activated Carbon Adsorption. Taylor \& Francus Group, Boca Raton, p. 479. 2005.

BORBA, C. E. Modelagem da remoção de metais pesados em coluna de adsorção de leito fixo. Campinas. Dissertação (Mestrado em engenharia Química). Universidade Estadual de Campinas, 145p, Campinas 2006.

CAMBUIM, K. B. Carvão de endocarpo de coco da baía ativado quimicamente com $\mathrm{H}_{3} \mathrm{PO}_{4}$ e fisicamente com vapor d'água: produção, caracterização e aplicações. 2009. 137p. Tese (Doutorado em Química Analítica) - Universidade Federal da Paraíba. João Pessoa, 2009.
CLAUDINO, A., Preparação de carvão ativado a partir de turfa e sua ulitização na remoção de poluentes. 2003. 90p. Dissertação (Mestrado em Engenharia Química) Universidade Federal de Santa Catarina, Florianópolis 2003.

Claudino, A.; MinOZZO, A. P.; Projeto de uma Indústria de Carvão Ativado. 2000. 7 p. Trabalho Referente à Disciplina de Projetos, Universidade Estadual do Oeste do Paraná.Toledo, 2000.

GONÇALVES, G.C.; MENDES, E.S.; PEREIRA, N.C.; SOUSA, J.C de. Produção de carvão ativado a partir de bagaço e melaço de cana-de-açúcar.

Acta

Scientiarum

Technology, Maringá, v. 28, n. 1, p. 21-27, 2006.

HARAGUCHI, F.K.; ABREU, W.C.; DE PAULA, H. Proteínas do soro do leite: composição, propriedades nutricionais, aplicações no esporte e benefícios para a saúde humana. Rev. Nutr. v.19, n.4, p.479-488, 2006.

INSTITUTO ADOLFO LUTZ. Normas Analíticas do Instituto Adolfo Lutz: métodos físico-químicos para análise de alimentos. $4^{\mathrm{a}}$ edição. São Paulo, 2004.

KRISSANSEN, G.W. Emerging health properties of whey proteins and their clinical implications. Journal of the American College of Nutrition, V. 26, p.723, 2007.

KURODA, E. K.; JÚNIOR, E. C. A.; BERNARDO, L.; TROFINO, J. C. Caracterização e escolha do tipo de carvão ativado ser empregado no tratamento de águas contendo microcistinas. Anais $\mathbf{2 3}^{\circ}$ Congresso brasileiro de engenharia sanitária e ambiental. 2005 
LIRA, H.L.; SILVA, M.C.D.; SANTOS, M.S.R.V. Microfiltração do soro do leite de buffalo utilizando membranas cerâmicas como alternativa ao processo de pasteurização. Ciência e tecnologia de alimentos, vol 29, 2009.

MALL, I. D., SRIVASTAVA, V. C., AGARWAL, N. K. "Removal of Orange-G and Methyl Violet dyes by adsorption onto bagasse fly ash - kinetic study and equilibrium isotherm analyses" Dyes and Pigments v.69, 210-223p., 2006.

MASEL, R. I. Principles of Adsorption and reaction on solid surfaces. New York: John Wiley e Sons Inc., 1996.

OLIVEIRA, M.S.C. Utilização de carvão ativado na adsorção de lactose e proteína do soro do leite. 2014. 54p. Dissertação (Mestrado em Ciências Ambientais) Universidade Estadual do Sudoeste da Bahia, Itapetinga 2014.

PEREIRA, R.G. Síntese de carvões ativados a partir resíduos agroindustriais e sua aplicação na adsorção de proteínas do soro do leite. 2012. 66p. Dissertação ( Mestrado em Engenharia de Alimentos) - Universidade Estadual do Sudoeste da Bahia, Itapetinga 2012.

RADHIKA, M.; PALANIVELU, K., Adsorptive removal of chlorophenols from aqueous solution by low cost adsorbent Kinetics and isotherm analysis, Journal of Hazardous Materials, B138, 116, 2006.

RENHE, I.R.T. O papel do leite na nutrição. Revista do Instituto de Laticínios Cândido Tostes, v 63, 43p, 2008.

SGARBIERI, V.C. Revisão: Propriedades Estruturais e Fisco-Químicas das Proteínas do
Leite. Brasilian Journal of Food Technology, v.8, n.1, p.43-56, 2005.

SILVA, D.J.; QUEIROZ, A.C. Análise de alimentos: métodos químicos e biológicos. Viçosa. 2002.

SMÍSEK, M.; CERNÝ, S. Active Carbon: manufacture, properties and applications. Elsevier, Amsterdam, 1967.

VIEIRA, A. P., SANTANA, S. A., BEZERRA, C. W., SILVA, H. A., DE MELO, J. C., DA SILVA FILHO, E. C., \& AIROLDI, C. Copper sorption from aqueous solutions and sugar cane spirits by chemically modified babassu coconut (Orbignya speciosa) mesocarp. Chemical

Journal, v.161, n. 1 p99-105, 2010.

FERNANDES, F. L. Modificações químicas em superfícies de carvões ativos de endocarpo de coco da baía e de bagaço de cana-de-açúcar visando adsorção de íon cloreto. 2004. 116 f. Dissertação (Mestrado em Química) Universidade Federal da Paraíba , João Pessoa, 2004.

\section{AGRADECIMENTOS}

A Universidade Estadual do sudoeste da Bahia - UESB pela concessão do laboratório e recursos para a realização do trabalho. 